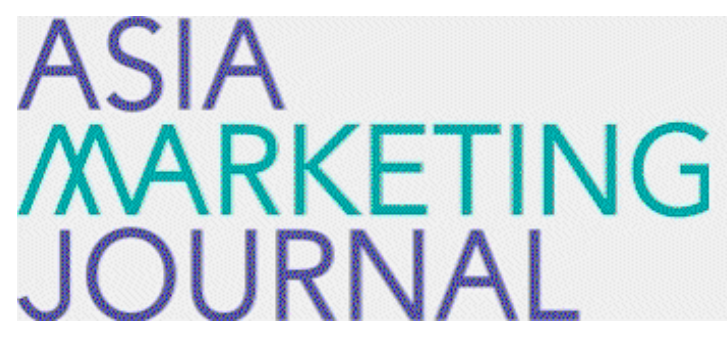

ASIA MARKETING JOURNAL

Volume 14 | Issue 4

Article 3

$1-30-2013$

\title{
What explains the failure of Google in the Korean market? The Impact of Multicultural PR Strategy
}

Hye Jung Kim

Won Seok Woo

Hyoung Goo Kang

Follow this and additional works at: https://amj.kma.re.kr/journal

Part of the Marketing Commons

\section{Recommended Citation}

Kim, Hye Jung; Woo, Won Seok; and Kang, Hyoung Goo (2013) "What explains the failure of Google in the Korean market? The Impact of Multicultural PR Strategy," Asia Marketing Journal: Vol. 14 : Iss. 4 , Article 3.

Available at: https://doi.org/10.53728/2765-6500.1499

This Article is brought to you for free and open access by Asia Marketing Journal. It has been accepted for inclusion in Asia Marketing Journal by an authorized editor of Asia Marketing Journal. 


\title{
What explains the failure of Google in the Korean market? The Impact of Multicultural PR Strategy*
}

\author{
Hyejung Kim** \\ Wonseok Woo*** \\ Hyoung-goo Kang*
}

The era of globalization provides us with both opportunities and threats. The success of a multinational corporation depends largely on its ability to adapt itself to new market environment. We believe that understanding and implementing multicultural PR strategy can be a key to the multinational corporations' success in foreign markets. We argue in this paper that even a global iconic company such as Google needs to focus on how to understand local consumers' needs and preferences before formulating and implementing PR strategy. Having a global hit product or service is not sufficient enough to be successful in some foreign markets. It is especially more evident in the industries where companies deal with individual consumers, and perceptions and sentiments play a large role in their purchase decisions.

The objective of this research is to find out the relationship between multicultural PR strategy and business performance. Therefore, our main hypothesis is: better implementation of multicultural PR strategy by a multinational corporation will result in higher performance in the foreign markets. To prove the relationship between multicultural PR strategy and performance, we designed a framework that uses Rudan's (2004) five rules for multicultural PR strategy.

It is a contribution to the business academics as there are very few studies that directly focus on and analyze the multicultural aspects of a multinational company's PR strategy. Through our research, we found strong evidence that there is a positive relationship between the level and effectiveness of a company's multicultural PR strategy and its performance in the foreign markets. This offers some meaningful implications to the managers of the multinational corporations and those who are considering going into a foreign market for the first time. We also suggested a way of measuring the implementation of multicultural PR strategy. By applying five rules for multicultural PR strategy to Google's PR activities, it allowed us to convert qualitative information into quantitative data. This kind of tool can be helpful for multinational corporations that want to evaluate their own PR activities.

Key words: multicultural PR strategy, multinational corporations, international PR strategy, localization and the five rules for multicultural PR strategy

\footnotetext{
* This research is supported by the grant from the National Research Foundation (Project No. 327-2010-1-B00201)

** Korea Health Promotion Foundation(leslie1982hj@gmail.com)

*** Ewha Womans University. Scranton College, Division of International Studies(wwoo@ewha,ac.kr), corresponding author

**** Hanyang University Business School (hyoungkang@hanyang.ac.kr)
} 


\section{Introduction}

Google Inc., one of the most powerful players in cyberspace, is not powerful any more in the Korean market. Its global market share in searching is almost $80 \%$ in Jul, 2009," ${ }^{1}$ which is more than $90 \%$ in some countries such as France, Germany, Hungary and Italy. On the other hand, its market share in Korea is a mere $3 \%$ in $2009 .{ }^{2)}$ There are various views on Google's unprecedented failure in Korean market, but we propose that Google's failure is related to its lack of understanding multicultural contexts. Google has failed in Korea because it jumped into the Korean market without multicultural PR strategy based on Korean Internet user's behavioral pattern. Through this research, we are going to find out how multicultural PR strategy affects business success-failure of Google Korea.

Multicultural PR strategy is taking an important role in multinational corporations' business policy as the globalization is being accelerated. In the era of globalization, so many multinational corporations are pushing into overseas market with the enhanced mobility. However, not every multinational corporation is successful and some of them go through hardship struggling to secure stable market share. It means that even if a multinational corpo- ration is very successful domestically, it could fail in other country's market. Therefore, for multinational corporations, to know how overseas market is different from their own market or whether they can apply the same business policy to overseas market is significantly important. Understanding cultural differences can be one of the measures to build the business strategy for overseas market. That's the reason why multicultural PR strategy is gaining more explanatory power these days.

There are several researches addressing multicultural PR strategy and localization strategy of multinational corporations. However, a majority of the researches tend to focus on comprehensive localization strategy of international corporations and are not specified on multicultural PR strategy. One of the researches dealing with multicultural PR strategy is cultural variance as a challenge to global public relations: a case study of the Coca-Cola scare in Europe by Maureen Taylor (2000). The author analyzed different public responses among European nations when the Coke product caused illness. An analysis of the national cultures of each European country showed that the public who live in nations that are high in uncertainty avoidance and power distance tend to react more strongly and quickly to perceived threats.

The author used the cultural dimension model

1) http://www.seosem.kr/24 (accessed on December 15, 2009 for the last time)

2) http://www.seosem.kr/57 (accessed on December 15, 2009 for the last time) 
which is suggested by Geert Hofstede (1983) to compare each national culture with one another. According to the Hofstede's model, there are five dimensions that form a certain national culture and they include power distance, individualism/collectivism, masculinity/ femininity, uncertainty avoidance, Confucian dynamism. Through her research, the author suggested that when a multinational corporation establishes PR strategy for overseas market, it can consider cultural differences based on Hofstede's model. However, there is no study that reveals the actual relationship between multicultural PR strategy and business success-failure.

Through our own research, we will look into how multicultural PR strategy affects business success-failure, especially multinational corporations' success-failure in overseas market. Our main proposition is the better implementation of multicultural PR strategy a multinational corporation has, the more successful performance it can show in overseas market.

\section{Literature Review}

Whereas few papers analyze how multicultural PR strategies influence the performance of global firms, many investigate marketing policies in multicultural settings. They find that cultural factors shape marketing strategies and their performances.

Mueller (1987) examined the role of culture within advertising content comparing the advertisements between Japan and U.S. market for similar goods. He concluded that cultural differences are not very dominant for both countries' consumers but tend to be varying in the degrees and it is portrayed through different usage of same appeals. He also found that contemporary Japanese ads little reflected traditional value of the group, but rather utilized the Westernized appeal of individuality and independence.

Bruce and Harbir (1988) found that entry mode selection is influenced by cultural context using multiple regressions controlling for firmand industry- level variables. It further suggested that transaction cost explanations for modes of entry choice should be qualified by factors stemming from the institutional and cultural context.

In line with the cultural issues, Cheng and Schweitzer (1996) analyzed and identified cultural values presented in Chinese and US television commercials. They found that the current Chinese advertising market is a "melting pot" of Western and Eastern cultures. They also found that symbolic values are more frequent in Chinese commercials while US commercials intend both symbolic and utilitarian values. Their finding also implicates "modernity and youth" dominate in both Chinese and US advertisings but it is not to be understood as 
Westernization of Chinese ads. In addition, they found that cultural values depicted in Chinese and US commercials have much to do with product categories.

Furthermore, Chiou (2002) investigated the effectiveness of different advertising appeals in Eastern societies which experienced rapid economic development using the Taiwanese market case as an example of emerging Eastern societies. The results imply that traditional appeals are gradually replaced by Western appeals in the Taiwanese market, but it cannot be interpreted as the diminution of traditional values. It showed that as a norm to enter a foreign market, marketers should understand the difference between individualistic Western societies and collectivist Eastern societies.

Fatt (1967) was one of the early scholars that noted the benefit and risk of localization of advertising in the era of internationalization. Universal or basic appeals do not mean not taking account of difference among people. The author argued that universal advertising appeals in local idiom can play more effectively. In other words, he proposed that marketers should pay attention to the need for international advertising but not to ignore the national tendencies towards advertising.

Tse et al. (1989) also examined changes in advertising themes in three Chinese societies, Hong Kong, the People's Republic of China (PRC) and Taiwan. Each Chinese society present different attitudes toward economic development: ads of Hong Kong emphasis on hedonistic values, PRC's ads still more dependent on conservative appeals, and Taiwan lies somewhere between Hong Kong and PRC.

Meanwhile. Han and Shavitt (1994) explored how individual and collectivistic cultures reflected in advertising focusing on cross-cultural differences in US and Korea ads. One of their two studies demonstrated that individual appeals are prevalent in US while collectivistic appeals are popular in Korea. The other study showed that the overall cultural differences are eased by product characteristics and argued that cultural differences are strong for shared goods but less powerful for individual goods.

Zhang and Gelb (1996) investigated product use conditions and their impact on the effectiveness of different advertising appeals - especially the effectiveness of ads appeals across contrasting culture, China versus US. The findings show that product use conditions play a moderating role on the effectiveness of culturally different ads appeals. Consumers reacted more favorable when the appeals matched product use condition.

Tai and Pae (2002) investigated standardization and customization strategies of multinationals TV advertising in China from consumers' perspectives. The authors found that Chinese consumers feel more familiarity on foreignsourced or standardized commercials and prefer it to local commercials, especially for durable goods. It was also observed that consumers ex- 
hibit more positive attitudes toward standardized commercials than localized ones.

In addition. Hymowitz (2007) provided managers with some ways to get generations to close culture gaps. According to the article, managers face additional challenges in the work place such as supervising multigenerational employees who have different expectations and ways of working. To cope with cultural gap between generations, corporations including IBM and Merrill Lynch are now putting their efforts to introduce new ways of management such as launching different learning venues to different generations. These new trials are not being spread to their foreign subsidiaries.

\section{Theory}

\subsection{Theoretical background}

There are different perspectives and arguments regarding Google's distinctively low market share in Korea - which is just over $3 \%$ - in spite of its prevailing global market presence. Most of the analyses focused on Google's product itself such as unfamiliarity of Google's appearance of main display. In the context of this conclusion, the only thing that Google can attempt to overcome its weakness is to change or remodel whole service pattern. Our interviews find that such strategy is against Google's rather strict policy of using global and common platform across countries.

However, when it comes to PR strategy, Google still has opportunities to cope with desperate situation in Korea. Kim (2000) discusses that the success of international corporation depends on the degree of localization in overseas market. According to his argument, localization strategy consist of production skill, marketing, human resource, organization, financing, and good relationship with local society. Oh (2001) emphasizes hollow effect of the corporation and argues hollow effect can be from PR activities of the corporations. It means that a multinational corporation can use hollow effect to form a positive image by implementing effective PR strategy.

We focus on multicultural PR strategy in this research rather than broad PR strategy because we believe that multinational corporations such as Google should not ignore cultural features in local market when it enters foreign markets. Taylor (2000) investigates the relationship between cultural variation and public response to crisis. Through her research, she found that there are differences in responding pattern among nations with different cultural features.

In this research, we argue that importance of PR strategy and the emergence of multicultural characteristics take a critical role in multinational corporations' success in foreign markets. As we mentioned earlier, we specifically focus 
on the different cultural aspects of entering foreign markets within a multinational company's PR and marketing strategies and look closely at the role of multicultural PR strategy on the overall performance in a foreign market

\subsection{Framework}

The objective of this research is to find out the relationship between multicultural PR strategy of a multinational corporation and its performance in the international markets. To prove this relationship, we design a framework that includes the following three steps.

For the first step, we gathered information on Google's PR activities that are performed in Korea. In this paper. PR activities include events, campaigns and publicities which aim at making a good relationship with customers.

Then, we scrutinized each PR activity that we collected through the first stage to figure out whether it has multicultural elements or not. For this purpose, we applied the five rules for multicultural PR strategy (Rudan, 2004) to those PR activities.

In the final step, we analyzed the data and explain the results. Analyzing data is taken by measuring the degree of multicultural characteristics in the company's PR activities based on the five rules that we introduce in the second stage. If a PR activity met all five rules, then we concluded that it achieved a high level of multicultural PR strategy. We also needed a goodness of performance for Google, Korea to analyze the relationship between multicultural PR strategy and the firm's performance. Our measure for this was Google's market share in Korea.

Then, we drew a matrix which consists of two dimensions. One is the level of multicultural PR strategy which is $\mathrm{X}$ variable and the other is market share percentage which is $\mathrm{Y}$ variable. If there are more sample cases and we put those in this matrix by analyzing sample corporations through the three steps above, the matrix would show a certain positioning map telling the relationship between $\mathrm{X}$ and $\mathrm{Y}$ variables in more reliable way.

\subsection{Conceptualization for theory development}

The most essential concept in our paper is how to measure the level of multicultural PR strategy. Rudan (2004) suggested that the five rules include integration, own research, cultural connectivity, perception and experts partnership. She argued that the more rules a PR strategy meets, the better multicultural PR strategy is. Each element can be described as below ${ }^{3}$ :

- Integration: If a company integrates mul-

3) Rudan, (2004). Five simple rules for launching a multicultural strategy. 
ticultural approach with public relations by creating separate multicultural departments, allocating marketing budget by segment and setting measurable goals for each segment, it could acquire and retain more customers than its competitors.

- Own Research: Demographic research, psychographic studies and sociological awareness are needed to adequately prepare for the planning phase. Research can be costly, but it is critical for sustainable success.

- Cultural Connectivity: Cultural connectivity is the ability to reach a consumer through their cultural context. For example, values, community, religion, lifestyles, ethnicity, race, sexual, orientation, class, country of origin, degree of acculturation and language can be considered.

- Perception: How communities see a company will influence how individuals will see it. The best way to conduct creating a good perception is to partner with national or local ethnic organizations.

- Experts Partnership: When a company plans a campaign, it should identify the appropriate resources and consider hiring an agency which is familiar with local culture or market trend.

Based on these 5 elements, we developed sub-factors that can be used to evaluate PR activities to find out whether or not certain PR activities are indeed multicultural. As a result.

〈Table 1〉 5 Categories and 17 Sub-factors for multicultural PR strategy

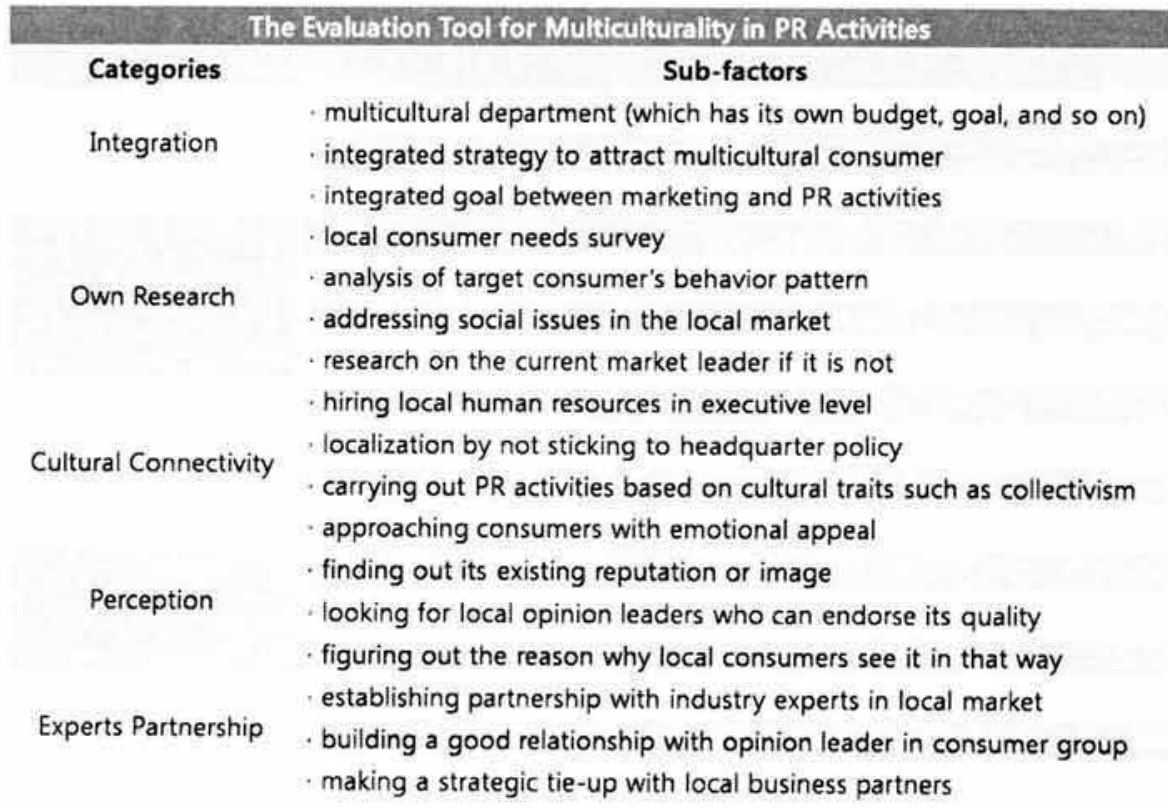


tool for checking the level of multiculturality have 5 categories and 17 sub-factors as shown in Table 1.

\section{Hypothesis}

We referred to Taylor (2000)'s findings to analyze Google's struggle in Korea.

She studied the relationship between cultural variance and public response to crisis and concluded that national culture which has high uncertainty avoidance and power distance show stronger and quicker reaction to perceived threats. It means that there are apparent differences in public response among nations that have diverse cultural identities.

We also took a note from the 5 Cultural Dimension Model (Hofstede, 1983). The 5 dimensions are power distance, individualism/ collectivism, masculinity/femininity, Confucian dynamism and uncertainty avoidance. As Taylor used this model in her research, this is representative model suggesting meaningful differences among cultures. In his study, Hofstede (1983) has identified that Korean culture has greater power distance, strong collectivism, masculinity, higher uncertainty avoidance and an explicit Confucian dynamism.

The findings and theoretical models mentioned above have significant implications for our paper. First of all, 5 Cultural Dimension
Model tells us that there is a cultural difference that cannot be ignored. It implicates that considering multicultural aspects in any organization - especially multinational corporations - is becoming a crucial element. In line with this, Taylor has proved that cultural difference affect public response and this finding can be extended to customers. Therefore, if a multinational corporation can take advantage of cultural differences by strategically performing PR activity, it could be more successful than when it cannot

Therefore, our hypothesis focuses on the relationship between a firm's multicultural PR strategy and its performance. Thus, our hypothesis is as follows:

Hypothesis: Better implementation of multicultural $P R$ strategy by a multinational corporation will result in higher performance in the foreign markets.

\section{Empirical Test}

To find out whether the hypothesis can be accepted or not, empirical test is a crucial phase in the whole process. We take Google's case for empirical test and more importantly focus on Google's PR activities and its market share in Korea. Based on these two aspects, we gather quantitative data as well as qual- 
itative data. . After collecting data, we start to analyze it using the matrix that we introduced briefly in the previous section.

\subsection{Internet search engines in Korea}

\subsection{1 "Google is the most powerful search engine in the world except in Korea."}

Search engine is literally to provide users with information searched. However, in the era of the Internet, search engine is something more than searching information. It can predominate over contact points on which all information and consumers meet together. Users make themselves connect with the Internet and at the same time they utilize search engine to find information or service they want. Also, they lock themselves in a certain Internet use environment by setting up preferred search engine site as the start page. In a nutshell, in the era of PC, MS Windows was the start point of all kinds of services, while in the Internet era online search engine such as Google becomes the start point. Therefore, as Internetbased information is distributed faster and broader, search engine becomes the first contact point with consumers looking for broad services.

While we did research on the global search engine market, we found out some interesting findings. First of all, Google's predominant position is noticeable. According to a survey con- ducted by comScore (market research company), Google has dominated $81.4 \%$ of global market share in April, 2009 and more than $65 \%$ of U.S. market share in June. 2009. In the rest of the world, especially in the Western European countries, Google has almost 90\% market share and Yahoo has 60\% market share in Japan. Thus, Internet search engines from U.S. have been leaders in the global Internet search engine market.

In Korea, however, Google or Yahoo is not the market leader. Naver, the leader in Korean Internet search engine market, is a native Korean firm and is followed by Daum which is another native Korean search engine. Google's market share in Korea is about $3 \%$ and there is little sign of change in this status for the foreseeable future. Thus, Korean search engine market is structured with showdown among domestic competitors, which compares sharply in the other global markets where competition is usually between domestic and foreign companies.

\subsubsection{Google VS. Naver in Korea.}

Google's technology for search engine is known to be the best. There is yet no match in collecting substantial web documents and converting them into indexation. In comparison, native Korean search engines are technologically inferior. Korean search engines rely on the efforts of web surfers instead of mathematical algorithm of Google. Google's approach 
is far better at locating information at web pages while the performance gap is less noticeable in finding websites. Then, how could Naver secure search engine market in Korea?

First of all, we believe that it is due to the difference in contents management. Google never collects contents by itself and adjusts search ranking with an intent to attract users. All contents are processed fairly by algorithms and Google makes users escape from Google site easily through the links found by Google. Thus. Google does not attempt to have users stay in its domain by providing search engine service. On the other hand, unlike Google, Naver has invested a lot on contents production and acquisition. Naver establishes information database through strategic tie-up with various information media and provides users with its own information such as JisikIN, Café, many dictionaries, geography and multimedia. In this way. Naver leads users to stay longer in its domain. If some searched information is outside Naver, it would be at the lowest part on the page.

Second, the different way of showing findings contributes to Naver's success. Google shows users search results without any editing. On the other hand, Naver provides users with categorized search findings by search keywords. For example, user can see just search findings arranged in a row through Google site, while user can get segmented information depending on its type such as website, dictionary, JisikIN, blog, news, video, web document, image, book, Café, specialist's information and local information. These categorized search findings enable users to attain information they want more easily. It also means that Naver provides users with a familiar search environment.

Third, Naver and Google have different types of initial (home) pages. Google just shows a simple screen which is optimized for searching. Naver, however, shows a colorful initial screen condensed with various information and diverse services. Although Google offers the tool through which users can customize initial page based on their own needs, information obtained from search engine is not re-organized to suit Korean information consumers' tastes.

Naver's predominance in Korean market is derived from its ability to create the convenient environment where users can easily produce and obtain the information they look for. For this reason, it is expected that Naver's strong market share will be stable for the time being. Naver's strategy in Korean market, which is somehow more insular and operates in a closed environment turned out to be much more effective than Google's. An analogous example in a different industry is large discount retailer market in Korea. Walmart had entered Korean market in the late 1990s, and struggled many years especially against strong local incumbent, E-mart with its "Korean style discount store" marketing strategy (Kim et. al, 2012) 


\subsection{Independent and dependent variable}

Based on the hypothesis mentioned earlier, there are two variables that can be indicators for testing. Independent variable is the level of multicultural PR strategy while dependent variable is the performance of corporation, which is measured by market share percentage. Independent variable is measured by counting the number of rules that PR strategy meets.

We measure independent variable as follows. If a PR activity meets 0-1 rules, it would fall in low group. If a PR activity meets 2 rules, it would be categorized in low-middle class. In this way, 3 rules for middle, 4 rules for middle-high and 5 rules for high. In Y variable, market share percentage will be measured from 0 to 100 .

\subsection{Gathering data}

\subsubsection{Dependent variable}

We gathered data on Google's market share in both Korean and global markets. The figures show Google's dominant market share in global markets, which contrasts sharply with its meager market share in Korea.

Figure 1 shows Google's prevailing market share among global Internet search engine companies. From Sep 2008 to Jul 2009, Google has been a market leader with a huge gap from other competitors with more than $80 \%$ market share. From this data, there is no doubt that Google is the one of the most successful multinational corporations in the world.

In contrast, Figure 2 reveals the dismal performance by Google in Korea. It shows that

〈Figure 1〉 Google's predominant global market share

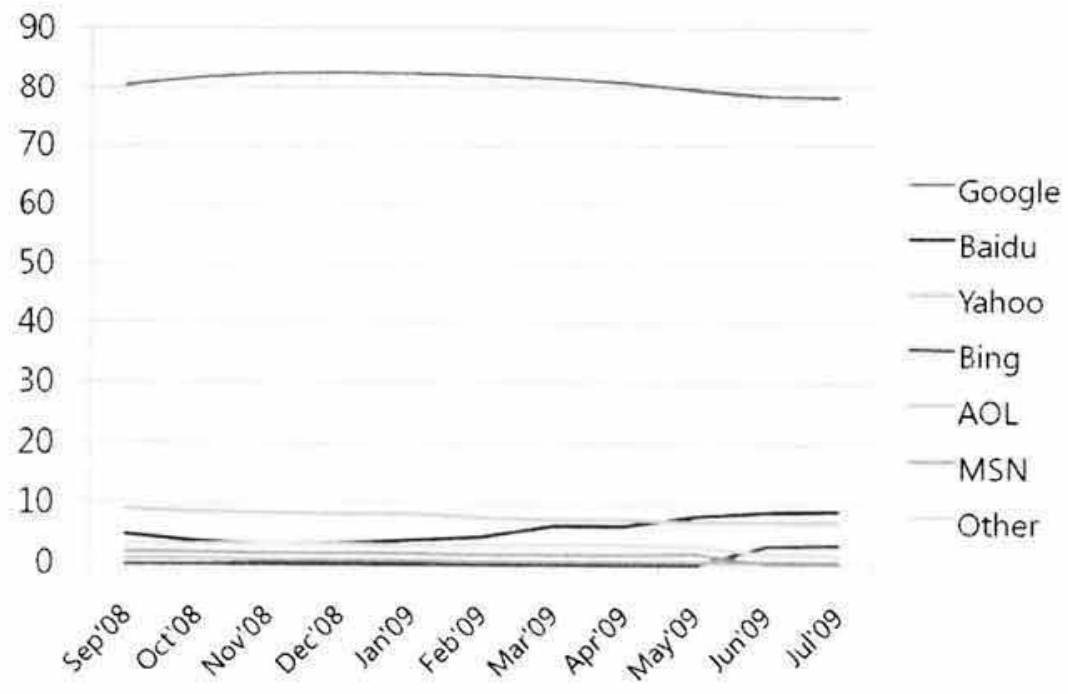


〈Figure 2〉 Google's low market share in Korea

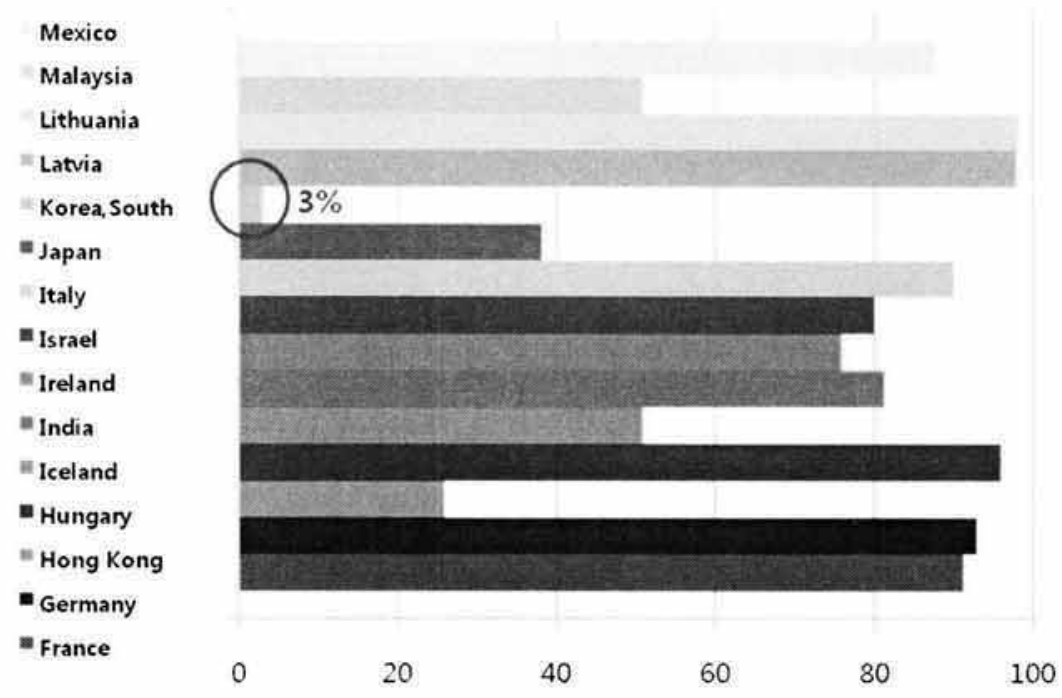

Google has considerably lower market share in Korea than any other countries with just 3\% share. It also demonstrates Google's very strong position in European nations. In fact, in most of the European nations such as France, Germany, Hungary, Italy, Latvia and Lithuania Google has more than $90 \%$ of market share. This fact may also exhibit the influence of regional or cultural factors on the multinational company's performance.

From these quantitative data, we confirmed Google's success in global markets as well as Google's big struggle in Korean market. A large gap between two status means that Google has been doing something wrong in Korea.

\subsubsection{Independent variable}

We measure Google’s PR activities qualitatively.
We analyze Google's PR activities by applying the aforementioned five rules for multicultural PR strategy to reveal whether those PR activities are actually multicultural or not. In addition, we interviewed several people who are working in such industries as Internet service, Internet search engine and Internet entertainment in order to get a professional view on the issue. Here are two representative PR activities that Google has been carrying out throughout the years.

PR activity 1: "Google Search Challenge"

- Target: University students (regardless of age, undergraduate or post graduate)

- Type: Event, Publicity

- Objective:

- To make potential customers experience Google's search engine. 
- To attract attention from both existing and potential customers

- To get an opportunity to increase awareness of Google brand

- Description in detail:

Google Korea held the event named Google Search Challenge for 6 days. It is a part of Google's marketing program, "The 100 things you can do with Google." Any university students who want to participate in the event can compete to win a prize. Top 20 competitors are given the opportunity to work for Google for 3 days and an MP3 player.

- Result: More than 110 thousands of page views

PR activity 2: "Google Map Partners Day"

- Target: About 300 business partners

- Type: Event

- Objective:

- To introduce Google's map service to potential business partners

- To share best practices and experiences with partners in strategic cooperation

- Description in detail:

Google Korea has provided 300 business partners with the opportunity to experience Google's brand new map service and share the best practice for strategic cooperation with Google by holding Google Map Partners Day. On that day, Google explained about the strength of Google map and possibility of business using the map service. This event drew attention from not only business partners but also general users.

- Result: Many promising business customers such as Daum Communication, Samsung Electronics, Seoul City, Soribada. Yahoo Korea, Interpark Shopping, Job Korea, Pandora TV, CJ Media, LG Electronics and SK Communications participated and showed interest.

\subsection{Data Analysis}

The data to be analyzed have been prepared through data gathering process. Now, we make those data have a meaningful application. For data analysis, we design a matrix that consists of two variables. Google's position is determined on the matrix from the quantitative and qualitative data.

First, analysis of quantitative data is a quite simple process because the market share percentage, the dependent variable, indicates an apparent position. 3\% market share of Google Korea can fall on the lowest part of the Y axis. At the end of the analysis section, we show the matrix again in a figure.

Second, analyzing qualitative data needs to be done more cautiously because there might be some biased views on that issue. To deal with this problem, we use an independent tool for analyzing qualitative data - the five rules 
for multicultural $P R$ strategy. As in the case of quantitative data analysis, the purpose of qualitative data analysis is also to find out the Google's position of the level of multicultural PR strategy on the matrix. Checking the number of rules that Google's PR activities meet is done in order to know which level is appropriate for Google.

The five rules for multicultural PR strategy can be presented like a check list as Table 2 . To simply the process of analysis, the choices are only in Yes or No type.

Based on this table, we evaluate Google's PR activities in Korea. To process this phase, each category is described in detail with sub-factors that we mentioned in theory section. Following is the analysis process and our findings regarding each rule after a number of interviews and extensive document research. We followed the interview guidelines in Huber and Power (1985) and Yin (1985).

\subsubsection{Integrations}

In this category, we focus on organizational integration within the Google Korea. The main questions are whether it has a multicultural department or not, whether it integrates multicultural PR strategies into whole marketing process or not, and whether it has a comprehensive goal that includes both PR and marketing activities.

Google Korea does not have a multicultural department that can be devoted to analyzing Korean culture and applying findings to its PR activities, nor does it have a comprehensive marketing process that includes multicultural PR activities. According to the interviewees we met, Google Korea does realize that Korean users have unique needs and sometimes express strong ill feelings against foreign companies, but Google is still hesitating to adapt to Korean market. It shows in their lack of multicultural PR strategy and dedicated department.

〈Table 2〉 Check list for evaluating multicultural PR strategy

\section{Google's PR activities are multicultural?}

Integration

Own Research

Cultural Connectivity

Perception

Experts Partnership
YES or NO

YES or NO

YES or NO

YES or NO

YES or NO 


\subsubsection{Own Research}

For evaluating whether Google Korea carries out its own research related to multicultural PR activities, there are 4 main factors to be checked. Those are local consumer needs survey, analysis of target consumer's behavior pattern, addressing social issues in the local market and research on the current market leader.

To grasp the circumstance in Korean market, Google Korea should have addressed social issues within its management strategy when it first entered Korean market. Although Google did a survey on basic local consumer needs in the beginning, the trend reflecting Internet users' behavioral pattern in Korea changes so fast. An interviewee said. "Korean Internet users like to make new words/ jargons regarding their interest and share it with other users. Unless foreign companies catch up with this trend, they would fail to attract Korean consumers." According to him, Google Korea should refer to how Naver is coping with consumer's dynamic needs and try to understand and satisfy Korean consumers' unique demands and preferences.

\subsubsection{Cultural Connectivity}

We believe that cultural connectivity is the most important element for successful multicultural PR strategy. If a company wants to accomplish cultural connectivity in its PR strategy, it should hire a local marketing/PR expert in executive level, carry out PR activities based on cultural traits such as collectivism, approach consumers with emotional appeal and not stick to existing headquarter policies.

Google Korea has recently been trying to improve cultural connectivity by hiring native Korean employees who can translate English database into Korean in more fluent manner. Also, Google Korea held the event for business partners to introduce its new map service so that potential business partners have a chance to meet Google's executive board. Despite these attempts, Google Korea is very subject to Google Global in implementing independent PR strategy in Korea. An interviewee pointed out that the reason why there have been no noticeable local PR activities done by Google Korea so far is because of Google headquarter's policy that emphasizes coherency. As a result. Google Korea's PR activities have not provided the momentum that it greatly needs to improve and widen its cultural connectivity with Korean consumers.

\subsubsection{Perception}

PR activities in corporations are all about building a good relationship between consumers and companies. The relationship is very much affected by individual perception even though it is not a logical one. Therefore, when a foreign company enters foreign markets, it should 
consider incorporating perception into its $\mathrm{PR}$ strategy. Perception includes existing reputation or image of the company, local opinion leaders' attitude toward the company and the reason why local consumers see the company in that way.

Google needs to find out consumer's attitude toward itself and try to build insight on Korean Internet Uses before implementing PR activities. An interviewee revealed, "When Google established R\&D center in Korea 8 or 9 years ago, there was quite a strong antagonism against foreign companies among Korean since the government supported many foreign companies when they push into Korean market. There were many desperate domestic corporations and individual consumers due to the economic recession. At that time, Google Korea ignored this Korea-specific emotional aspect of consumers' perceptions, and the ignorance became the biggest mistake Google Korea made."

\subsubsection{Experts Partnership}

For foreign companies, establishing partnership with local experts is one of the ways to adapt to local market environment and establish multicultural PR strategy without time consuming mistakes. If a company plans to make a partnership with local experts, it can consider establishing partnership with experts in the same industry in local market, building a good relationship with opinion leaders within consumer groups and making a strategic tie-up with local business partners.

Google Korea has not been a good example for having rich partnership with experts in local market, especially with opinion leaders of consumer groups, but it begins to show a little interest in attracting opinion leaders who are usually heavy Internet users. According to the interviewee, Google Korea just started to execute soft communications with consumers by operating official bloggers for Google Korea, which is quite unprecedented for Google in other countries. However, Google Korea needs to consider more diverse partnership such as local research agency, PR agency and cross-industrial tie-up to look for new opportunities for multicultural PR activities.

According to our analysis, Google's PR activities did not satisfy most of the five rules for multicultural PR strategy. Google's PR activities tend to be focused on one-time event and it seemed that there is no strategic and coordinated approach to PR activities. Therefore, Google's PR activities fall in the low level of multicultural PR strategy on the $\mathrm{X}$ axis. The completed matrix is shown in Figure 3.

Appendices summarize our discussion in table format. They also provide the description on the Korean market leader (Naver). It is clear that Google Korea is \{low, low in whereas Naver is at \{high, high\}. There certainly are many other possible explanations regarding why Google is unsuccessful in Korea. Through in- 
〈Figure 3〉 Google's position on the matrix

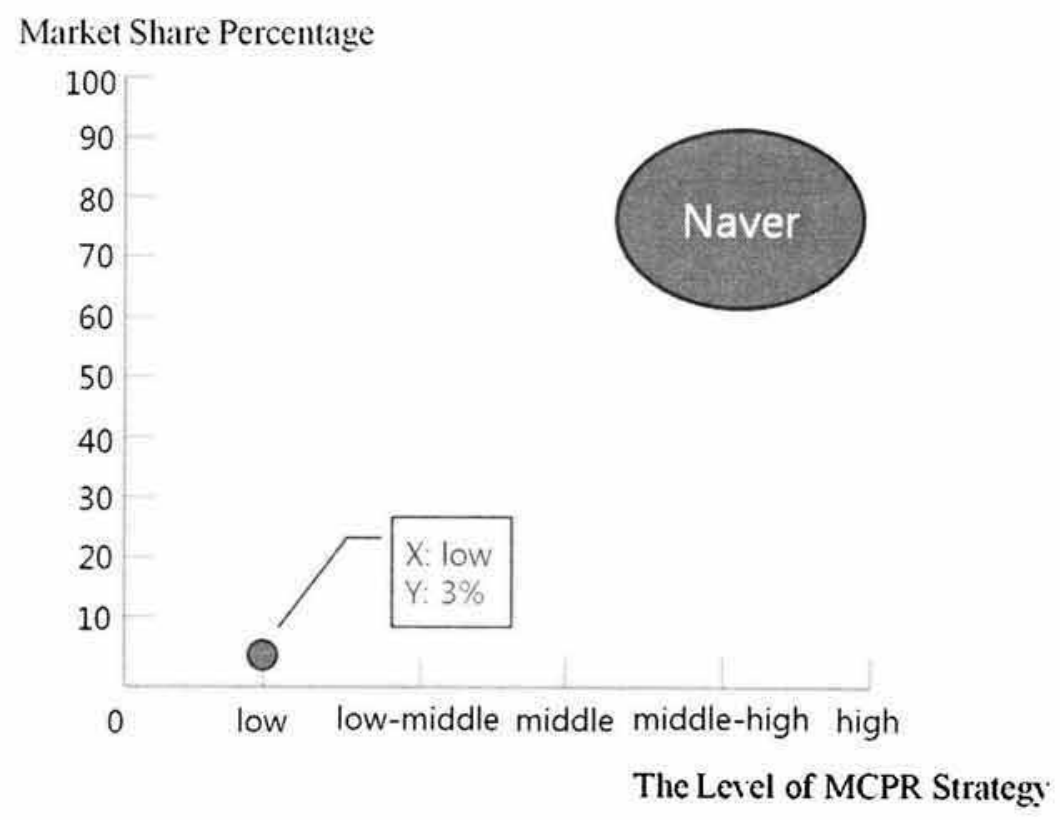

terviews and our analysis, we found that Google Korea's multicultural PR strategy is one of the main factors that can explain its struggle in Korean market.

\section{Conclusion}

The era of globalization provides us with both opportunities and threats. The success of a multinational corporation depends largely on its ability to adapt itself to new market environment. We believe that understanding and implementing multicultural PR strategy can be a key to the multinational corporations' success in foreign markets. We argue in this paper that even a global iconic company such as Google needs to focus on how to understand local consumers' needs and preferences before formulating and implementing PR strategy. Having a global hit product or service is not sufficient enough to be successful in some foreign markets. It is especially more evident in the industries where companies deal with individual consumers and perceptions and sentiments play a large role in their purchase decisions. Therefore, we set out to prove our hypothesis: better implementation of multicultural PR strategy by a multinational corporation will result in higher performance in the foreign markets. Through this research, we could offer some contributions and also are faced with limitations that need to be taken 
care of in future studies.

First, we focused on the relationship between multicultural PR strategy and a firm performance. It is a contribution to the business academics as there are very few studies that directly focus on and analyze the multicultural aspects of a multinational company's PR strategy. Through our research, we found strong evidence that there is a positive relationship between the level and effectiveness of a company's multicultural PR strategy and its performance in the foreign markets. This offers some meaningful implications to the managers of the multinational corporations and those who are considering going into a foreign market for the first time.

Secondly, we proposed a different way of measuring the implementation of a multinational corporation's multicultural PR strategy. By applying five rules for multicultural PR strategy to Google's PR activities in Korea, it allowed us to convert qualitative information into quantitative data. This kind of tool can be helpful for multinational corporations that want to evaluate their own PR activities.

While we can show some fruitful results, there still remain a few things that need to be dealt with in the future effort. Above all, following research needs to increase the number of samples to generalize the hypothesis and results because we took only one case of Google Korea and compared it with domestic players.

One more thing that should be covered is diversifying measures. In this paper, we meas- ured multinational corporations' performance by just looking at market share numbers. However, it would make our findings more robust if succeeding research can come up with more diverse ways of measuring a multinational company's performance in a foreign market.

〈Received May 1. 2012〉

〈Revised December 10. 2012〉

〈Accepted December 21. 2012〉

\section{References}

Doer, J., Moritz, M. Brin, S., \& Page, L. 2004. The Weakness of Google. Economist, 379: 63-64. Cheng, H. \& Schweitzer, J. C. 1996. Cultural values reflected in Chinese and US television commercials. Journal of Advertising Research, 36(3): 27-45.

Chiou, J. S. 2002. The effectiveness of different advertising message appeals in the eastern emerging society: using Taiwanese TV commercials as an example. International Journal of Advertising. 21(2): 217-236.

Fatt, A. C. 1967. The danger of 'local' international advertising. Journal of Marketing. $31(1): 60-62$.

Han, S. P. \& Shavitt, S. 1994. Persuasion and culture: advertising appeals in individualistic and collectivistic societies. Journal of Experimental Social Psychology, 30(4): 326- 350. 
Huber, G. P. \& Power, D. J. 1985. Retrospective reports of strategic-level managers: guidelines for increasing their accuracy. Strategic Management Journal, 6 (2): 171-180.

Hymowitz, Carol. 2007. Managers find ways to get generations to close culture gaps. Wall Street Journal, July 9: B1.

Kim, C. K., Chun, M., Han, J., Kim, M..Park, J.. \& Kim, J. Y. 2012. A Case Study of Shinsegae E-mart: How E-mart Became the Number One Distribution Company even against Economic Crisis and the Entry of Walmart? Asia Marketing Journal, 14 (3): 7-26.

Kim, N.K. 2002. Burger King Corporation. Journal of Food Science and Industry. Jun: 1-5.

Kim, Y.G. 2000. Theoretical study on localization strategy of international corporation. Social Science Research, 7: 115-146.

Kim , Y.W. \& Cha, H.W. 2002. The emerging conflict between traditions and changes: Exploring the Korea-style public relations. Korea Speech Gazette, 46(5): 5-42.

Kogut. B. \& Singh, H. 1988. The effect of national culture on the choice of entry mode. Journal of International Business Studies, 19(3): 411-433.

Korzenny. F. 2008. Multicultural marketing and the reasons why. Journal of Advertising Research, June: 173-176.

Taylor, M. 2000. Cultural variance as a challenge to global public relations: A case study of the Coca-Cola scare in Europe.
Public Relations Review, 26: 227-293.

Mueller, B. 1987. Reflections of culture: an analysis of Japanese and American advertising appeals. Journal of Advertising $\mathrm{Re}^{-}$ search, (June/July): 51-59.

Oh. M.Y. 2001. Evaluation of Multicultural Corporations and Halo Effect: Implications of International Public Relations. Public Relations Research, 5(2): 186-214

Rudan A. 2004. Five simple rules for launching a multicultural strategy. Public Relations Tactics. August: 19.

Tai, S. H. C. \& Pae, J. H. 2002. Effects of TV advertising on Chinese consumers: local versus foreign-sourced commercials. Journal of Marketing Management, 18: 49-72

Tse, D.K., Belk, R.W. \& Zhou, N. 1989. Becoming a consumer society: a longitudinal and cross-cultural content analysis of print ads from Hong Kong, the People's Republic of China, and Taiwan. Journal of Consumer Research, 15(March): 352-363.

Wakefield. I. 2008. Theory of International Public Relations, the Internet, and Activism: A Personal Reflection. Journal of Public Relations Research, 20: 138-157.

Yin, R. K. 1985. Case Study Research: Design and Methods. Thousand Oaks, CA: Sage Publications

Zhang, Y. \& Gelb, B.D. 1996. Matching advertising appeals to culture: the influence of products' use conditions. Journal of Advertising, 25: 29-46 


\section{〈Appendix A〉}

\section{Evaluating PR activities of Google Korea: "Google Search Challenge"}

\begin{tabular}{|c|c|c|}
\hline \multicolumn{3}{|c|}{ Google's PR activities are multicultural? } \\
\hline The Five Rules & $\begin{array}{c}\text { Activity } 1 \\
\text { "Google Search Challenge" }\end{array}$ & Result \\
\hline Integration & $\begin{array}{l}\text { - Integration means creating separate multicultural departments, } \\
\text { allocating marketing budget by segment and setting measurable } \\
\text { goals for each segment. } \\
\text { - "Google Search Challenge" looks like one-time event rather than } \\
\text { sustainably integrated PR activity. }\end{array}$ & NO \\
\hline Own Research & $\begin{array}{l}\text { - The target of this event was university students. Although we } \\
\text { are not sure whether Google carried out its own research on their } \\
\text { customers or not, just targeting certain demographic group is not } \\
\text { enough to be multicultural research. }\end{array}$ & NO \\
\hline Cultural Connectivity & $\begin{array}{l}\text { - This is the most important part of multicultural PR strategy. } \\
\text { "Google Search Challenge" is a kind of culture-based PR activity } \\
\text { because this is carried out only in Korea and managers in Google } \\
\text { showed their interest about Korean Internet users' behavioral } \\
\text { pattern. }\end{array}$ & YES \\
\hline Perception & $\begin{array}{l}\text { - The concept of perception in multicultural settings means that } \\
\text { people is affected by national or local ethnic organizations. } \\
\text { - This event does not target a group of national or local ethnic. }\end{array}$ & NO \\
\hline Experts Partnership & $\begin{array}{l}\text { - This element can be proven by contact with managerial staffs in } \\
\text { Google. }\end{array}$ & N/A \\
\hline
\end{tabular}




\section{〈Appendix B〉}

Evaluating PR activities of Google Korea: “Google Map Partners Day”

\begin{tabular}{|c|c|c|}
\hline \multicolumn{3}{|c|}{ Google's PR activities are multicultural? } \\
\hline The Five Rules & $\begin{array}{c}\text { Activity } 2 \\
\text { "Google Map Partners Day" }\end{array}$ & Result \\
\hline Integration & $\begin{array}{l}\text { - "Google Map Partners Day" is focused on gathering potential } \\
\text { business partners and introducing Google's new technology for } \\
\text { map service. } \\
\text { - It is also hard to say that this is multicultural. }\end{array}$ & NO \\
\hline Own Research & $\begin{array}{l}\text { - This event is for business partners rather than general customers. } \\
\text { It is unlikely that Google performed its own research on the } \\
\text { individual consumers for the event planning. }\end{array}$ & NO \\
\hline Cultural Connectivity & $\begin{array}{l}\text { - We are not sure whether this kind of event is held in other } \\
\text { countries, but it is possible that Google seems to consider Korean } \\
\text { culture. } \\
\text { - According to Hofstede, Korean culture has high uncertainty } \\
\text { avoidance. This could be why Google offers this face-to-face } \\
\text { event. }\end{array}$ & YES \\
\hline Perception & $\begin{array}{l}\text { - Just like the "Google Search Challenge" event, this event has } \\
\text { nothing to do with national or local ethnic groups. }\end{array}$ & NO \\
\hline Experts Partnership & $\begin{array}{l}\text { - This element can be proven by contact with managerial staffs in } \\
\text { Google. }\end{array}$ & N/A \\
\hline
\end{tabular}




\section{〈Appendix B〉}

\section{Evaluating PR activities of Naver}

\begin{tabular}{|c|c|c|}
\hline \multicolumn{3}{|c|}{ Naver's PR activities are multicultural? } \\
\hline The Five Rules & Comprehensive PR activities & Result \\
\hline Integration & $\begin{array}{l}\text { - Naver, as a Korean native Internet search engine, doesn't need to } \\
\text { have multicultural department to adapt to different culture. } \\
\text { However, it is recommended that Naver focus on integration of } \\
\text { research department and service development department as more } \\
\text { customized and user friendly services attract more users. } \\
\text { - Naver has already been operating a team like that and most PR } \\
\text { activities such as events, advertisements and news publicity are } \\
\text { focused on cultural traits. }\end{array}$ & YES \\
\hline Own Research & $\begin{array}{l}\text { - Naver carries out surveys on its user's interest and attitude toward } \\
\text { its services periodically and it develops new services or revises } \\
\text { existing services based on those survey results. } \\
\text { - In addition. Naver has a unique team that provides up to date } \\
\text { information on Internet user's trend or industrial status by watching } \\
\text { TV programs, radio and Internet media }\end{array}$ & YES \\
\hline Cultural Connectivity & $\begin{array}{l}\text { - "JisikIN" service has become a killer application of Naver. } \\
\text { - This service is rooted in the belief that Korean people are more } \\
\text { prone to sharing knowledge with others. } \\
\text { - Naver detected this behavioral pattern and developed PR strategy } \\
\text { using this representative service. } \\
\text { - For Naver, cuitural connectivity means customizing its services to } \\
\text { meet consumers' needs. } \\
\text { - As a result, Naver has } 75 \% \text { share in Korean search engine market. }\end{array}$ & YES \\
\hline Perception & $\begin{array}{l}\text { - Naver is not known for outstanding searching facility, but famous } \\
\text { for offering categorized and segmented information to the users. } \\
\text { - Naver's PR strategy utilizes user's perception toward its services }\end{array}$ & YES \\
\hline Experts Partnership & $\begin{array}{l}\text { - This element depends on Naver's overseas market strategy. } \\
\text { - In Korea, it doesn't need to form a partnership with experts, because } \\
\text { Naver itself is familiar with Korean culture and market trends. }\end{array}$ & N/A \\
\hline
\end{tabular}

